\title{
PARÂMETROS PARA UMA PESQUISA HISTÓRICO-JURÍDICA SOBRE A OBRA DE JOSÉ LINS DO REGO
}

\section{PARAMETERS FOR A HISTORICAL-LEGAL RESEARCH ABOUT THE WORK OF JOSÉ LINS DO REGO}

${ }^{1}$ João Paulo Mansur

\section{RESUMO}

Este artigo averiguará o problema da possibilidade de se estudar juridicamente a obra de José Lins do Rego, escritor conhecido por buscar relatos literários que se assemelhassem à realidade do nordeste patriarcal brasileiro. O direito, entendido como um fenômeno social, precisa estar, de alguma maneira, presente na obra com fidelidade à realidade daquela sociedade. Por isso, perguntou-se se seria e como seria possível a obra de arte aproximar-se da realidade para relatar a mesma. O teórico Antônio Cândido guiou na tarefa. Das seis possibilidades de comparação entre a literatura e a sociedade que Antônio Cândido elabora, três foram julgadas como frutíferas para analisar a obra de José Lins do Rego. Com esses três instrumentos metodológicos, foram expostos elementos sociais e jurídicos dos livros de José Lins do Rego. Esse procedimento permitiu concluir pela possibilidade de um estudo jurídico da obra do autor paraibano. Então, pôde-se dimensionar metodologias, objetivos gerais e específicos e justificativas para a pesquisa.

Palavras-chave: José lins do rego, Regionalismo literário, Cultura jurídica, Historia do direito, Direito e literatura

\begin{abstract}
This article will investigate the problem of the possibility of studying legally the work of José Lins do Rego, writer known for seeking literary reports that resembled the reality of brazilian patriarchal northeast. The law, understood as a social phenomenon, must be, somehow, present in the artwork with fidelity to the reality of that society studied. Because that, it wondered whether it would be possible and how it would be possible the artwork to approach to the reality to narrate it. The academic Antonio Cândido guided this article in the task. From the six possibilities of comparison between literature and society that Antonio Cândido elaborates, three were judged as fruitful to analyzing the work of José Lins do Rego. With these three methodological instruments, social and legal elements of José Lins do Rego's books were exposed. This procedure led to concluding by the possibility of a legal study of the paraiban author's work. So it was possible to figure methodologies, general and specific objectives and justifications for research.
\end{abstract}

Keywords: José lins do rego, Literary regionalism, Legal culture, History of law, Law and literature

\footnotetext{
${ }^{1}$ Mestrando em Direito pela Universidade Federal de Minas Gerais - UFMG, Minas Gerais (Brasil). E-mail:.jpmansur@gmail.com
} 


\section{INTRODUÇÃO}

As obras literárias do autor paraibano José Lins do Rego (1901 - 1957) fazem parte do cânone das obras clássicas da literatura brasileira. Pertencente ao movimento regionalista da década de 30 do século passado, José Lins do Rego compõe suas narrativas a partir de uma interessante característica estilística. Segundo nossa percepção da obra, os fatos e situações sociais não possuem muito valor em separado. As orações são curtas e secas. Porém, são capazes de, ao passar da leitura, criar um ambiente que se pretende homologo ao identificado com nordeste brasileiro da primeira república. A escrita ganha organicidade na relação. Nós temáticos reproduzem fatos, situações sociais, aspectos culturais, crendices e aspectos jurídicos em sentido amplo, que, no conjunto, efetivam uma imagem no horizonte.

Observando essa particularidade da obra de José Lins do Rego, surgiu a intenção de realizar leitura sócio-jurídica da obra zeliniana. Se, de fato, José Lins conseguira alcançar os objetivos dos escritores da geração nordestina de 30, que era transcrever o ambiente local nas suas mais diversas manifestações, então, sua obra pode oferecer concretude às explanações histórias, sociológicas e de história do direito. Por via reflexa, pode se tornar elemento didático para a compreensão da sociedade e das instituições jurídicas atuais, que estão dentro de contexto diverso daquele momento de transição que representa o nordeste da primeira república. Hoje, em termos gerais, consolidou-se no Brasil o projeto dos modernos Estados de Direito, ainda em formação na primeira república de José Lins.. Este artigo, assim, discorre sobre problematizações preliminares à pesquisa e tem por objetivo traçar ideias sobre os procedimentos metodológicos, os métodos, nortear objetivos gerais e específicos e os possíveis resultados para uma pesquisa jurídica sobre a obra de José Lins do Rego. São parâmetros e questionamentos preliminares à pesquisa, que visam perquirir sua viabilidade.

Dessa forma, este artigo se perguntará como a obra de arte pode relacionar-se com a sociedade de forma a oferecer instrumentos para a compreensão social e jurídica desta. Caso estivéssemos completamente enganados sobre o caráter histórico da obra de José Lins do Rego, sendo ela, na verdade, composta de pura ficção, não se justificaria uma pesquisa que buscasse reconstruir aspectos jurídicos da sociedade brasileira da primeira república com o seu auxilio. A literatura de José Lins apenas atrapalharia a compreensão histórica. Seria o mesmo que analisar juridicamente a sociedade fabulosa exposta em algum livro ficcional de vampiro, desse tipo comercial que faz sucesso como best-seller atualmente. Quem sabe alguém tenha prazer em tal empreitada, mas não se justifica realizá-la a nível de pós- graduação. 
A partir da pergunta proposta, traz-se para este artigo, - embora ao nível da pesquisa, seja preciso aprofundar o projeto em teoria da literatura -, uma exposição analítica de Antônio Cândido, autor de "Literatura e Sociedade", sobre seis maneiras de se aproximarem obras literárias da análise histórica e sociológica da realidade. Aparentemente, destacam-se três como de fecundidade para a especificidade da pesquisa proposta. A primeira forma de aproximação interessante enfoca aspectos da obra literária a partir da posição social em que o autor, no caso, José Lins do Rego, estava inserido. Importa o aspecto biográfico de José Lins. A segunda maneira de aproximação entre literatura e sociedade analisa a estrutura interna da obra buscando homologia entre fatos e situações da obra, analisadas em isolado, com fatos e situações da realidade. A terceira forma de análise julgada eficiente almeja entender interpretativamente e sistematicamente relações sociais para aplicá-las à literatura. A cada uma dessas três formas, será destinada uma subseção da seção 2 (dois).

Com essas três possibilidades de aproximações, espera-se validar a hipótese sobre a capacidade de a literatura de José Lins refletir aspectos sociais importantes para a compreensão da sociedade e do direito nordestino. Assim, se estará apto a modelar aspectos metodológicos para a pesquisa, ponderando objetivos gerais e específicos realizáveis, resultados esperados e dimensionando as justificativas.

\section{Formas possíveis de análise do conteúdo social em obras literárias.}

Um problema preliminar a que toda pesquisa que envolva direito e literatura deve ter consciência se refere a um tema que a teoria literária vem buscando reposta, em um ato que ora expande a análise a disciplinas humanas e sociais colaterais, ora fecha-se em si, para tentar tratar da relação entre a obra literária e a sociedade. "Se e em que sentido existe relação entre a obra literária e a realidade da sociedade" é a questão. Questão que pode ser reformulada na dualidade autor e sociedade: é possível o autor libertar-se do "espírito do povo" para criar obra ficcional totalmente autônoma? Se sim, em que medida?

A afirmação de que a literatura reflete aspectos da sociedade soa a nós como um truísmo, mas essa concepção representa algo historicamente novo que pode remontar a noções modernas captadas pela filosofia iluminista e pelo romantismo alemão. Nos dizeres de Antônio Cândido "isto se esboçou no século XVIII, quando filósofos como Vico sentiram a sua correlação com as civilizações, Voltaire, com as instituições, Herder, com os povos." (CÂNDIDO, Antônio, 2006, p.29). 
Visando elucidar analiticamente essa relação, destacando diferenças dentro do truísmo, Antônio Cândido enumera seis formas possíveis, não exaustivas, de correlacionar a obra literária e a sociedade: A primeira forma de aproximação busca construir chaves interpretativas da sociedade, levando em conta elementos de estudos sociológicos, como as condições políticas, econômicas, materiais, etc., ou seja, se apodera de perspectivas sociológicas e filosóficas e procura arranjá-las em paralelo nas obras literárias elaboradas dentro da sociedade analisada ou cujo enredo a retrata. Candido chama atenção para possíveis falhas nessa postura, como a tentativa de encontrar na literatura soluções para questões que a filosofia e a sociologia debatem acaloradamente ao analisar a realidade.

Segunda possibilidade pensada por Antônio Cândido aproxima-se à primeira, porém, sem a pretensão de uma sociologia globalizante que explique toda a organicidade da sociedade a partir de relações causais. Essa segunda possibilidade atentar-se-ia sem pretensão sistemática para fatos e comportamentos em geral ocorridos na obra literária e verificaria a sua correspondência na sociedade. Trata-se de um modelo mais simples e comum, livra-se em maior grau do caráter interpretativo que o primeiro possui e não corre muitos riscos de deixar lacunas e fatos literários sem interpretação.

O livro Oliver Twist, de Charles Dickens, analisado sob a primeira ótica, permitiria uma análise social entre o enredo do jovem órfão e pobre, que é conduzido à criminalidade juvenil, e o processo de industrialização e individualização moral da sociedade burguesa, indiferente à miséria social. Porém, essa análise do primeiro tipo não explicaria, segundo Cândido, o seio da bondade reconciliatória da avó, contrária ao individualismo da sociedade burguesa. Em suma, Cândido demonstra um problema de homologia entre a obra e a teoria social utilizada para interpretá-la: a obra literária também é ficcional e livre dos conhecimentos sociais e científicos. Nesse sentido, o autor é poiético, cria a realidade de alguma forma. Aluísio Azevedo consultou médico amigo para obter conhecimento sobre envenenamento por estricnina, mas modificou seus efeitos em "O homem" para dar dramaticidade à obra. Mas, além do problema da homologia e da liberdade criativa, Cândido aponta também as supostas insuficiências das mesmas teorias sociais sistemáticas em compreender o mundo, pois o reduz a regras gerais. Se, inclusive, dentro da filosofia e dentro da sociologia há disputas para afirmar quem melhor explica o mundo, que essa disputa se restrinja àquelas áreas, já que a inserção da literatura como um intermediário, para Cândido, em nada satisfaria aquele objetivo de explicar a realidade.

Terceira perspectiva de análise da obra literária a partir de elementos da sociedade passa para um plano puramente sociológico ao perquirir a aceitação, o destino e a ação 
recíproca da obra em relação ao público. Seria uma sociologia do gosto literário. Quarta possibilidade identificada por Antônio Cândido se refere ao estudo do autor enquanto pertencente a uma posição e função social. Aparentemente, Cândido fala da função da "classe lógica dos autores", ou seja, essa possibilidade de análise busca compreender o estatuto e o papel do literato, do intelectual em geral, dentro da sociedade e as suas responsabilidades na formação da mesma. Cândido não se refere aos aspectos específicos de cada autor individualmente. Embora Cândido não a perquira, essa é outra possibilidade de analise da relação entre literatura e sociedade: focar no sujeito individual de determinado autor, considerando aspectos sócio-biográficos contributivos para a obra.

Quinta possibilidade de aproximação que Cândido traz ocorre quando se busca a função política e ideológica das obras e dos autores dentro de determinada sociedade: o papel mercadológico e alienante dos best-sellers sobre vampiros e afins na sociedade contemporânea seria um exemplo de hoje para esse tipo de pesquisa exposto por Cândido, ou ainda uma análise da telenovela como propagandista de modos de vida. A última possibilidade a que Cândido se propõe a expor se refere à investigação sobre as origens de determinados estilos e gêneros, como as relações genéticas entre a tragédia grega e a sociedade helena.

Essas possibilidades elencadas por Antônio Cândido ajudam a distinguir analiticamente possibilidades de aproximações entre a obra literária e a sociedade, saindo do mero truísmo de que as obras dependem da sociedade. As duas primeiras formas poderiam ser chamadas de "internas", por se preocuparem com a estrutura da obra, enquanto as quatro últimas são análises "externas", por analisarem problemas propriamente sociológicos da obra com o público ou com o autor. Antes de prosseguir, é preciso lembrar que Antônio Cândido escreve alguns dos artigos que depois vieram a compor o livro "Literatura e Sociedade" com foco na perspectiva da crítica literária, em que o aspecto de análise sociológica seria apenas um entre os possíveis de consideração na atividade crítica, cujo suposto valor de referência seria o estético. A bela arte literária, em sua visão, poderia ser lida sociologicamente e ter seu valor atribuído enquanto boa reprodutora de fatos e análises sociais - análises internas. Porém, essa seria apenas uma das possibilidades para o juízo estético da arte. De fato, a independência da crítica está presente como questão fundamental para a teoria literária contemporânea. Nesses termos, aquelas duas primeiras maneiras de análise enfatizam o aspecto social como fato constitutivo da obra, embora outras aproximações fossem possíveis para o juízo estético, como, por exemplo, o estilo de escrita e o uso do vocabulário. 
Como se deve, portanto, a início de conversa, analisar a obra de José Lins do Rego enquanto enfatizando elementos da realidade social? É claro que a distinção de Antônio Cândido é elementar e, para um juízo tão complexo que é a relação entre literatura e sociedade, outros aspectos precisam ser depurados durante a pesquisa. Aliás, o próprio Antônio Cândido o faz, trazendo aspectos de uma dialética hegeliana para a sua teoria literária, ao afirmar a interioridade das características sociais, que são externas à obra, como perspectiva suprassumida de uma perspectiva de identidade imediata da obra com a realidade e de outra perspectiva de completa separação hermética da obra em relação ao meio social. Nota-se o esquema hegeliano de identidade imediata da consciência, a separação da autoconsciência e a razão absoluta de unidade mediatizada. Na perspectiva hegeliana de Cândido, o caminho correto estaria, portanto, em uma interiorização da realidade (exterior) na obra que pressuponha a separação.

\footnotetext{
Quando fazemos uma análise deste tipo, podemos dizer que levamos em conta o elemento social, não exteriormente, como referência que permite identificar, na matéria do livro, a expressão de uma certa época ou de uma sociedade determinada; nem como enquadramento, que permite situá-lo historicamente; mas como fator da própria construção artística, estudado no nível explicativo e não ilustrativo (CÂNDIDO, Antônio, 2006, p.16-17)
}

Essa construção a partir da noção de razão hegeliana explica a resposta de Cândido ao problema sobre a liberdade do autor frente ao mundo, referido no início do capítulo: o problema da liberdade do autor perante o mundo social. A liberdade do autor em compor o mundo partilha, para Cândido, do mesmo esquema dialético que Hegel emprega para compreender a liberdade e a razão enquanto realizadas na natureza e no espírito do povo. Decerto, outras aproximações filosóficas caminharão em sentido distinto, como a estética kantiana, cuja compreensão de liberdade faria permitir maior autonomia do artista. Mas já estamos desviando do pensado para este artigo. Adentrar na perspectiva hegeliana de Cândido serve tão somente para mostrar problemas e possibilidades teóricas e filosóficas nos horizontes. Agora, nesta exposição preliminar de pesquisa, bastam as seis perspectivas basilares trazidas por Antônio Cândido, que servirão como boas ferramentas de análise para se definir procedimentos metodológicos, objetivos e justificativas da pesquisa.

\subsection{Realidade jurídico-social e a obra de José Lins do Rego a partir de elementos}

\section{biográficos}

Para avaliar juridicamente a obra de José Lins do Rego, o que supõe uma análise social em sentido amplo, três análises das propostas por Cândido podem ser frutíferas. Em primeiro 
lugar, levar-se-á em conta a posição social específica de José Lins no que se refere à nossa adição à quarta possibilidade elencada por Antônio Cândido, analisando características específicas do autor que contribuíram na construção de uma literatura com conteúdo de uma sociedade específica. Enquanto neto de senhor de engenho e conscientemente escritor daquela realidade nordestina da primeira república vivenciada por ele, aparenta ser de fundamental importância se creditar, preliminarmente, confiança geral da narrativa zeliniana enquanto verossímil, de existência de situações de ocorrências possíveis e em certo grau habituais naquela sociedade.

O livro "menino de engenho", por exemplo, primeiro romance de José Lins do Rego publicado, viera como projeto de o autor biografar a vida de seu avô, um senhor de engenho, que, na ficção, é representado pela personagem do coronel José Paulino. Mais tarde, com a publicação do livro biográfico "Meus verdes anos", algumas situações fáticas narradas na obra ficcional se assemelharam tanto às autobiográficas que a imaginação dos críticos e dos leitores se questionaram acerca da veracidade real de fatos ficcionais instigantes, por exemplo, quem sabe se diga, os eróticos momentos do relacionamento amoroso entre Carlos de Melo e Maria Alice narrados em "Banguê", sequência do "Menino de engenho".

Suas experiências no internato do Colégio Diocesano Pio X são memórias que auxiliaram na composição do livro "Doidinho", que narra as experiências da personagem Carlos de Melo nos estudos colegiais e as suas transformações psicológicas em relação ao tamanho do velho José Paulino, que era dono do mundo enquanto o mundo, na compreensão do jovem, se restringia aos engenhos, mas que, cosmopolitamente, representava cada vez menos poder conforme o jovem ultrapassava as fronteiras do engenho. Carlos de Melo, então, é o descendente de senhor de engenho que realiza aquele êxodo, primeiro a alguma cidade regional, para cursar o colegial; depois, à capital, para estudar Direito. Eis a figura do bacharel, presente em outras obras do movimento nordestino, como "A bagaceira", de José Américo de Almeida, e que fora vivenciada pelo próprio José Lins do Rego, que formou-se bacharel em direito na Faculdade do Recife.

Dessa forma, o elemento biográfico permeia todas as narrativas que José Lins classificou como o "ciclo da cana de açúcar". São seis obras - "O menino de engenho", "Doidinho", "Banguê", "O moleque Ricardo", "A usina" e "Fogo morto" - com a mesma sequência narrativa, mudando, às vezes, somente as personagens principais e, em "o moleque Ricardo" e em "doidinho", o ambiente. A crítica literária, muito vasta em se tratando de José Lins do Rego, possui como reflexão invariável essa relação da obra de José Lins do Rego com a sociedade a partir da posição social privilegiada do autor para elaborar relatos memorialísticos. 
São exemplos, cada qual à sua interpretação, as análises de Afonso Arinos de Melo Franco, (MELO FRANCO, Afonso Arinos de, 1991); Olívio Montenegro (MONTENEGRO, Olívio, 1991); Brito Broca (BROCA, Brito, 1991) e Osmar Pimentel (PIMENTEL, Osmar, 1991). A título de exemplo, José Aderaldo Castello, ao falar da relação memorialística do ciclo da cana, do qual "Menino de engenho" é matriz geradora, analisa :

\begin{abstract}
(...) em que não seria mais possível a ficção disfarçar a memória. A compreensão, portanto, de qualquer obra do ciclo da cana de açúcar, quer pelo aspecto da reelaboração da memória, com o seu poder de presença dominante, quer em termos de criação ficcional, depende intimamente do conjunto, mas a partir da aceitação daquela ideia da matriz geradora, fecundando um fruto que se multiplicará. Talvez só esse fruto deva ser isolado para investigarmos os sulcos profundos de cortes verticais, desnudando sementes. E quem os espia e os investiga é o próprio memorialista, nessa ideia que formamos de seu primeiro romance. (CASTELLO, José Aderaldo, 1991, p. 232)
\end{abstract}

Os romances do chamado "ciclo do cangaço", outra classificação do próprio José Lins do Rego, não partilham do mesmo privilégio memorialístico, embora as terras do velho José Paulino chegassem até o sertão, local proeminente do banditismo sertanejo. "Pedra Bonita" e "Cangaceiros" migram o ambiente da zona da mata para a caatinga a fim de ter como pano de fundo social a miséria da vida sertaneja, sujeita à violência das tropas policiais e dos cangaceiros e aos santos messias. A economia muda de atividade com a interiorização: da cana para o gado. José Lins do Rego presenciou, conforme narrado em "Menino de engenho", "Fogo Morto" e "Meus verdes anos", visita amistosa do cangaceiro Antônio Silvino, homem real e personagem ficcional, ao seu avô. Depois, em 1938, em companhia de Graciliano Ramos [RAMOS, Graciliano; LEBENSZTAYN, Ieda (org.); SALLA, Thiago Mio (Org.), 2014, p.67], visita Antônio Silvino na cadeia. Embora a experiência histórica imediata de José Lins do Rego com o cangaço se restrinja a poucos momentos, o ambiente nordestino vivenciado por ele era marcado por causos, histórias e especulações sobre esse fenômeno do bandidismo, o que lhe torna, a princípio, sujeito de posição social legítima para ficcionar com verossimilhança.

Os outros quatro livros que completam a obra de José Lins são ditos autônomos, pois não se relacionam aos dois outros ciclos, que compõem, cada um deles, um desenvolvimento de enredo único. As obras autônomas são "Pureza, "Água-mãe", "Eurídice" e "Riacho Doce". "Pureza" e "Riacho doce" não mudam por completo o relato social. Os problemas da exploração dos trabalhadores do eito, bem descrita no final de "Doidinho" e em "Banguê", demonstra as formas de opressão a que estavam submetidos, desde a econômica propriamente dita, até a destruição familiar, o direito inquestionável à propriedade do senhor e a perversidade 
sexual do senhor de engenho. "Mandava em tudo. Os cabras chegavam no alpendre para pedir. Eu dava e negava as coisas, botava para fora (...) Eram meus. Podia mandar derrubar a Mata do rolo quando quisesse, comer todas as mulheres do Santa Rosa. Eram minhas." (REGO, José Lins, 2011a, p.151). No Recife, José Lins do Rego vivenciou as transformações dos problemas sociais com a urbanização e industrialização, que foram inseridos em "Moleque Ricardo". "Riacho doce" e "Pureza" são também romances socais no mesmo sentido. "Pureza" explora os resquícios na escravidão na mentalidade dos senhores de engenho e a opressão sexual às mulheres fora dos engenhos, que, embora livres, sofrem pelos preconceitos de uma sociedade de costumes patriarcais.

"Água-mãe" aprofunda o problema do conflito de costumes em sociedades tradicionais, especificamente, a dos moradores - donos de salinas, atividade não muito rentável, e pescadores de camarão - , ao redor da lagoa Araruama, região de Cabo Frio - RJ, em contraposição a costumes modernos impostos à região com a chegada de uma família de industriais do Rio de Janeiro. O enredo muda a localidade, mas mantém, em nossa interpretação social, a mesma estrutura que guiou o ciclo da cana: permanecem os temas da ruína econômica dos engenhos nordestinos e da mudança de costumes a partir da urbanização e dos estudos nas capitais urbanas, porém, adaptados ao novo contexto. Ou seja, José Lins do Rego, que, a essa altura, já morava no Rio de Janeiro, continua com a mesma problemática da decadência econômica e temas afins, adequando-a à realidade da capital brasileira. Eurídice passa na própria cidade carioca, com temática de crime passional e com problemas urbanos. De fato, o único livro que pode ter a característica de autonomia mais acentuada, mas que pode ser visto como ponto de chegada para a transição que permeia as outras obras.

Enfim, as experiências pessoais de José Lins do rego continuam fundamentais nos "livros autônomos", seja por manter o embrião da decadência e da transformação social, apenas adequando-o ao novo contexto, ou para, no caso de Eurídice, compor o ponto de chegada de uma nova realidade, fundada a partir da superação lógica da anterior. José Lins mantém, a princípio, a capacidade de sujeito social competente para narrar com verossimilhança a realidade dos temas trazidos nos romances autônomos.

Assim, conclui-se raciocínio preliminar sobre a biografia de José Lins de forma confiante na sua capacidade de reproduzir problemas, tensões, situações sociais com referência à realidade, tendo em vista a sua posição social, assim como sua competência de expor relações jurídicas nas narrativas, devido à sua formação em direito na Faculdade do Recife. Assim, a pesquisa deverá realizar vasto levantamento biográfico sobre a obra de José 
Lins, bem como analisar sua postura como homem do cotidiano e como cronista de jornal. Das crônicas, muitas das quais compiladas nas obras "Ligeiros Traços", "O cravo de Mozart é eterno" e "Flamengo é puro amor", podem ser extraídas informações e pensamentos sobre sua visão cotidiana a respeito de questões corriqueiras.

\section{2 - Realidade jurídico-social e a obra de José Lins do Rego a partir da homologia entre fatos e situações literários e fatos e situações históricos.}

A categorização de Antônio Cândido sobre as possíveis aproximações entre a literatura e a sociedade oferecerá uma segundo instrumento de aproximação eficiente para a análise da obra de José Lins: o segundo exposto, que, segundo Cândido, permite comparar fatos históricos com os fatos narrativos. Essa perspectiva de análise, como dito, despreocupa- se com pretensões históricas e sociológicas mais generalizantes, que buscam relações de causas e efeitos na constituição da sociedade. Ao contrário, faz-se uso de comparações entre a literatura e a história, em uma concepção mais factual desta. Há também buscas por situações e características típicas, mas sem a perspectiva de descobrir seus fundamentos, relações causais, explicações ou justificativas.

Analisando sob essa perspectiva as obras de José Lins do Rego, um primeiro aspecto a ser ponderado se refere aos elementos tempo e espaço das obras. Temporalmente, a estilística zeliniana evolui com as narrativas posteriores a "Menino de engenho". Raras são as alusões diretas às datas em que se passam as obras. Em vez, José Lins contextualiza as obras em referências a fatos históricos reais. Em "Pureza", a narrativa se desenvolve junto à primeira guerra mundial. Para localizar cronologicamente "Doidinho", há alusão à virada do milênio, à presidência da república de Afonso Pena e às disputas políticas na Paraíba entre as oligarquias rurais, chefiadas pelos Dantas, e as elites urbanas, de líder João Pessoa. "Água- mãe" se desenvolve tendo a Guerra do Contestado como referência cronológica. "Moleque Ricardo" situa-se cronologicamente com auxílio das greves do Recife a partir do final da década de 10. Em "Pedra Bonita", a Guerra de Canudos e as secas de 1877 e 1904 são as referências de onde parte a noção temporal. Enfim, já na demarcação cronológica a comparação fática com a realidade é necessária para apreender o tempo narrativo. Por outro lado, são elementos externos trazidos à obra pra lhe impregnar de conteúdo histórico importante.

$\mathrm{O}$ aspecto espacial também deve ser desenvolvido com o olhar para a realidade. As exaustivas citações, lugarejos, vilas e cidades são, via de regra, alusões a localidades 
existentes, embora possam ter, hoje, mudado de nome, ou mesmo mudado o status administrativo. Os diversos nomes de engenho citados no ciclo da cana de açúcar necessitam, porém, de maior pesquisa histórica. Por exemplo, o engenho "Santa Rosa", que, entre os nove engenhos do cel. José Paulino, era a sede da casa-grande, corresponde ao engenho do corredor, propriedade do avô de José Lins do Rego, onde este nasceu. Portanto, os locais de desenvolvimento dos enredos partilham da realidade fática.

No que se refere a fatos e situações sociais típicas desenvolvidas nas narrativas, pode-se crer, a título preliminar, em um algo nível de verossimilhança, quando comparado com textos históricos. Ali estão eventos do cotidiano nordestino que representavam a vivência habitual dos seres humanos. Por exemplo, em "Menino de engenho", "Doidinho", "Fogo Morto" e "Banguê" encontram-se elementos que a historiografia configurou como característico da sociedade patriarcal moderna. Sérgio Buarque de Holanda, em "Raízes do Brasil" expõe informações sobre a autossuficiência do engenho, que mantinha em suas terras artífices que supriam as necessidades da casa-grande em termos de serralheiro, ferreiro, sapateiro, etc. Mestre Amaro, um dos protagonistas de "Fogo morto" representa um desses artífices. A relação próxima que esses oficiais possuíam, em geral, com os coronéis, sentando- se à mesa da casagrande, José Lins do Rego expõe em prosa o que Sérgio Buarque conta historicamente, assim como outros temas uníssonos nas obras de José Lins e em "Raízes do Brasil", a exemplo do analfabetismo de muitos coronéis, a falta de íntima religiosidade, as relações adúlteras e exploradoras dos mesmos com negras libertas, o uso de técnicas agrícolas predatórias, aspecto exposto em "Pureza" para o qual Holanda destina substancial espaço. O colégio e as faculdades de direito como destino dos filhos dos proprietários de engenho, exposto por Holanda, é eixo narrativo pelo qual avançam não menos do que quatro livros do ciclo da cana de açúcar. Aspectos arquitetônicos da casa-grande que chamaram atenção de Gilberto Freyre são expostos em diversas passagens, como especial relevância para o alpendre, de onde o coronel avistava as terras e gritava aos trabalhadores do eito. Em torno da função de banco da casa-grande, onde os coronéis enterravam moedas de ouro e prata, motivo pelo qual as estruturas se abalavam e as tábuas do assoalho rangiam, o que dava origem ao folclore de casas mal assombradas, José Lins do Rego destina uma parte inteira do livro "Água-mãe" para narrar a casa-branca, mansão abandonada e "mal assombrada", onde homens passavam a noite endoidecendo gananciosamente em procura de ouro enterrado. 
A comparação entre a obra de José Lins e documentos históricos e trabalhos históricos expositivos evidencia o êxito do mesmo em concretizar os planos do modernismo regionalista nordestino, alicerçado nas ideias do manifesto regionalista de Gilberto Freyre, que era o de retratar os elementos locais do nordeste nas obras de arte. Nos dizeres de Bernardo Borges Buarque de Holanda: "segundo Gilberto Freyre, cabia ao artista exprimir a originalidade da cultura, a fim de ser reconhecido em âmbito internacional e de apresenta-se com autonomia perante o mundo" (HOLLANDA, 2012, p.81). Freyre e Lins do Rego foram amigos pessoais desde os vinte e poucos anos de cada. A ligação entre os dois se deu, conforme depoimento zeliniano, da maneira mestre e discípulo, tendo em vista o encanto que Freyre, já experiente estudante em universidades americanas, exerceu sobre o matuto José Lins. Narra ele o primeiro encontro entre os dois e o mundo que se abriu, retirando-o de vida boêmia de despreocupado: "Foi numa tarde de Recife, do nosso querido Recife, que nos encontramos, e de lá para cá a minha vida foi outra, foram outras as preocupações, outros os meus planos, as minhas leituras, os meus entusiasmos" [REGO, José Lins; LÊDO, Ivo (Org.), 2004, p. 49].

Gilberto Freyre, principalmente nos primeiros livros, possuía estilo de análise e escrita típica da sociologia americana, em que as preocupações sistemáticas estão em segundo plano frente às inferências empíricas, o que implica forma de pensar a realidade com menos riscos de incongruências à teoria central, permitindo inserção de fenômenos diversos na análise, embora, como esse método, se perca um aspecto relacional dos fatos. José Lins do Rego escreve sobre levantamento realizado por Freyre nos tempos do Jornal Diário de Pernambuco: "Escreveu ali sobre tudo que era da vida de uma região, das manifestações folclóricas, das revoluções libertárias, dos poetas, da fabricação de rendas, das artes plásticas, das igrejas, dos conventos, do açúcar, do algodão, das fibras, do comércio, dos holandeses, das relações internacionais, dos escravos." [REGO, José Lins; LÊDO, Ivo (Org), p. 57]. A leitura das obras de José Lins do Rego demonstra como sua narrativa é, em parte, tributária à de Freyre, tendo em vista o largo horizonte de nós temáticos que enfrenta conscientemente para formar ambientes orgânicos. Além dos já citados, podemos elencar "nós temáticos" que José Lins do Rego traz da realidade para sua literatura: do folclore temos o lobisomem em "Fogo Morto" e "Banguê"; a mula sem cabeça e mãe d'água em "Pedra Bonita". As histórias de Trancoso presentes em "Histórias da velha Totônia", mas narradas em tantos outros livros, descrevem os contos do imaginário infantil. O misticismo e o sincretismo religiosos em "Pedra Bonita", "Cangaceiros" e "Água-mãe", sem falar nas expressões culturais, como o repentista e o cantador, em "Pureza" e "Pedra bonita". Sobre estrutura urbana da vilas, estão presentes a feira, a praça, 
o trem, a igreja. "Menino de engenho" é um manifesto em louvor à culinária nordestina. As beatas e as solteironas são assuntos recorrentes. As donzelas, raparigas e prostitutas narram a trágica realidade da mulher. Romeiros e retirantes expõem os êxodos e abandonos da terra a que se submetiam os nordestinos. Sobre a economia do nordeste, o açúcar, o algodão e o gado, assim como impactos de cada plantio na vida do trabalhador, como a possibilidade ou não de coexistirem com roças de subsistência dos moradores, ou a quantidade de mão de obra necessária pela lavoura. Há relatos sobre os conhecimentos científicos sobre saúde e as doenças que atacavam o povo, como a tuberculose, em pelo menos, "Pureza", "Doidinho", "Moleque Ricardo" e "Usina".

Esses são apenas alguns nós temáticos a partir dos quais José Lins busca a organicidade de suas obras. Enfim, tudo leva a crer, preliminarmente, que a comparação fática da realidade com os fatos narrativos, conforme o modelo proposto por Antônio Cândido, é muito eficaz em se tratando de analisar socialmente a obra de José Lins do Rego, principalmente, se se tiver em conta a relação de proximidade pessoal e intelectual de nosso autor com Gilberto Freyre, que tinha como concepção de análise da realidade o levantamento específico de nós temáticos.

No que se refere a nós jurídicos, objetivo específico da pesquisa, José Lins do Rego, embora bacharel desinteressado pelas leis, não deixou de fora de sua análise esse problema fortíssimo que era o Direito na sociedade patriarcal nordestina. Os nós temáticos encontrados envolvem direito de família, do modo a ser perquirido o status civil dos enamorados não casados, com possíveis reflexos no direito penal, devido ao crime de defloramento (Pureza). Também a contextualização das formas de dissolução do casamento vigente na época se faz necessário tendo em vista romances como "Água-Mãe". A doação de filhos a terceiros, como forma de adoção extralegal, como em "Pedra Bonita" e "Pureza". Consequência desses nós de direito de família são os reflexos no direito de sucessão, com o problema da regulamentação jurídica da herança dos filhos mulatos bastardos, que os senhores de engenho espalhavam pelo eito sem o reconhecimento, presente, pelo menos, em "Menino de engenho", "Moleque Ricardo" e "Banguê". No que se refere ao direito de propriedade e direito contratual, precisa- se analisar a relação jurídica dos moradores dos engenhos com os proprietários de engenho, aspecto encontrado em "Banguê", "Pureza" e "Fogo morto".

Acerca de direito social, trabalhista e previdenciário, José Lins do Rego narra, em uma das obras mais forte, "Moleque Ricardo", a vida de jovem homônimo que percorre o caminho que diversos negros libertos fizeram rumo à cidade, em movimento de êxodo rural que caracterizou a urbanização desordenada e despreocupada no Brasil. Romance fortíssimo que mostra a situação deplorável a que se submetia o proletariado urbano, que não gozava de direitos 
sociais trabalhistas e previdenciários, ou mesmo de direito à saúde ou assistência social. A narrativa expõe as dificuldades decorrentes das ausências de seguros de acidente do trabalho, desemprego, aposentadoria, auxilio reclusão, pensão por morte para esposa e descendentes menores, etc. Torna-se, assim, romance capaz de ambientar o leitor a uma configuração jurídica de Estado liberal, levando sua imaginação a um mundo com os malefícios da ausência de regulamentação social no ambiente urbano. Para o campo, "Banguê" cumpre a tarefa de expor as condições trabalhistas lamentáveis no ambiente rural.

Interconecta-se ao problema social a configuração do direito penal e do direito processual penal descrita na obra de José Lins do Rego. Em "Moleque Ricardo", mostra-se a criminalização das greves e as prisões sem julgamento prévio dos grevistas, assim como a criminalização dos jovens infratores que roubam alimentos para sobreviver, enredo típico também de outras sociedades liberais nos primórdios do capitalismo, como "Os miseráveis" na França, "Oliver Twist", na Inglaterra, e, mesmo no Brasil, posteriormente, "Capitães de Areia". "Pedra Bonita" e os "Cangaceiros" relatam o banditismo e exige estudo acerca do poder de polícia das tropas volantes, que, aparentemente, agiam em estado de exceção, a exemplo da sobreposição da autoridade do Juiz de Direito pelo Tenente Maurício, em "Fogo morto". Há, ainda, excepcional problemática acerca do júri e as interferências exercidas pelo poder político sobre ele. Além disso, sobre o júri ainda, dois outros aspectos importam: o conflito entre o direito estatal e a aceitação social no que se refere à vingança privada, além do problema dos crimes passionais e a legitimidade social de tais atos.

Sobre direito tributário, há os divertidíssimos relatos dos contrabandistas atravessadores de aguardente. Direito eleitoral e administração da justiça são a chave de ouro da análise jurídica da obra de José Lins do Rego, onde se manifestam em excelências as problemáticas do patriarcalismo, como o, por vezes, conflito, por outras, a complementaridade ou a concorrência, de "competência" entre o poder político do coronel e o poder estatal. Em "Água-mãe", porém, romance ambientado no Rio de Janeiro, as relações promíscuas que antes se davam entre os coronéis e o poder governamental, agora tem aqueles substituídos pelos burgueses.

Dessa forma, concluindo, preliminarmente, por uma inserção consciente de fatos sociais na literatura, a obra de José Lins, a partir da procura de nós temáticos homólogos aos encontrados em textos históricos e jurídicos, torna-se instrumento valioso para a compreensão do direito, especificamente, e da sociedade nordestina, em caráter geral. Permite transplantar os fatos que o historiador acessa por documentos históricos para a vivência cotidiana, o que confere concretude e uma visão integral da composição daqueles nós e fatos dentro da sociedade. 
Mais do que exemplificações para as percepções históricas e para as normas do Direito, a literatura de José Lins do Rego é capaz de mostrar suas as funções sociais e suas relações com um todo orgânico da sociedade, como Ivan Cavalcanti, talvez com algum exagero ao falar da "história oficial", intui ao falar sobre "Menino de engenho":

\begin{abstract}
Assim como a mais importante fase importante da literatura brasileira, em poesia, foi a romântica na segunda metade do século XIX, a mais significativa, em prosa, foi aquela inaugurada por José Américo de Almeida, em 1928, com A bagaceira (...) E é a este período (década de 1930, basicamente) que corresponde a notável literatura regional do Nordeste brasileiro: personagens, linguagem, meio ambiente, temas e problemática daquele brasileiríssimo Nordeste. E é a esse período que pertence o ciclo da cana-de-açúcar, do autor, onde se situa, pioneiro, Menino de engenho. E Zé lins foi, sem dúvida, o grande mestre, o mais importante (tenho que alardear juízo de valor) escritor regional de todos os tempos em nossa literatura. A literatura, em geral, traz à tona tudo que a história (oficial ou não) por princípio e metodologia costuma evitar: gentes, sua índole, suas paixões e fraquezas, os cotidianos, o disse-me-disseram, o humano dos personagens. Conhecer o Nordeste sem debruçar-se sobre a obra dos ficcionistas é não conhecer o Nordeste: vocabulário, trajes, hábitos e costumes, a paisagem, a impiedosa seca, os cajueiros, o litoral. Zé Lins fez sua parte, melhor que ninguém. Só então é que se pode discutir, transposições, açudes, plataformas, culinária, agricultura, ligas camponesas, Grupo dos Onze, cangaço. E Brasil, portanto. (PROENÇA CAVALCANTI, Ivan, 2012, p.13)
\end{abstract}

Para essa segunda forma de aproximação entre literatura e sociedade que Antônio Cândido expõe, a principal tarefa da pesquisa será se socorrer de textos históricos sobre a sociedade brasileira e, especificamente, sobre o Direito, de forma a buscar as correspondências entre fatos e situações históricos e fatos e situações literárias. Em relação ao direito, as principais fontes para essa aproximação ocorrerá na avaliação das legislações e das instituições estatais de Direito da época.

\title{
2.3 - Realidade jurídico-social e a obra de José Lins do Rego a partir de teorias sistemáticas.
}

As pesquisas em Direito e Literatura cresceram em quantidade nos últimos tempos. Porém, as dificuldades já demonstradas por Antônio Cândido em aproximar a literatura da sociedade, em sentido geral, criam grandes empecilhos às pesquisas jurídico-literárias, que, normalmente, tendem somente à metodologia factual demonstrada no capítulo anterior. A comparação entre fatos reais e as obras de José Lins do Rego possui, não obstante, um limite notório na elucidação das sociedades narradas. Abordar-se-á, agora, esse limite ao nível histórico-jurídico e ao nível histórico-sociológico. Entra-se no terceiro instrumento fértil para aproximação entre a literatura de José Lins do Rego e a sociedade, o primeiro proposto por Cândido, no qual aspectos interpretativos e sistemáticos são utilizados para analisar a literatura. 
Em patamar jurídico, uma análise factual da literatura, em consequência ao segundo método proposto por Antônio Cândido, tende a analisar leis e instituições jurídicas enquanto fatos, ou seja, no modelo de Estado moderno, regras e órgãos postos pelo autoridade estatal. Essa possibilidade seria coirmã da teoria positivista do direito aplicada na análise literária. Por isso, segue o raciocínio silogístico. Procura descobrir a norma jurídica válida na sociedade narrada pela obra literária. Vai à obra e identifica casos de transgressão à regra e, para concluir, observa a aplicação da regra jurídica ao caso literário, advertindo se a solução exposta pelo autor coincide ou não com a devida pela regra jurídica. Qual seja, a obra literária serve tão apenas a caráter exemplificativo, são os casos concretos buscados na literatura, em vez de buscá-los na jurisprudência ou nos jornais.

Decerto, a comparação factual será necessária, mas não será única forma utilizada para compreensão do fenômeno jurídico. José Lins do Rego narrou grandes ambientes aos quais só se pode adentrar juridicamente caso se largue de mão mitologias modernas de que o direito é tão somente a lei do Estado de Direito (GROSSI, Paolo, 2007). Assim, sai-se da confortável objetividade factual das leis para penetrar no aspecto teórico, filosófico e político dos pensamentos jurídicos. Por exemplo, sobre o júri, José Lins do Rego, enquanto bacharel em direito pela faculdade do Recife, estava habituado com a discussão jurídica e política acerca dessa instituição. Enquanto discussão política, o júri fora disputa de poder entre as oligarquias decadentes e as elites urbanas. Normalmente defendido por aquelas e negado por estas, o júri era questionado enquanto instituição que permitia manobras políticas dos senhores de engenho em detrimento à aplicação racional das leis. José Lins, através de um estilo narrador que dá voz a vários personagens, inclusive com posições antagônicas, reproduz esse conflito politico-filosófico em inúmeros livros, "Pureza", "Banguê", "Menino de Engenho", "Doidinho" e na de narrativa mais marcante sobre o júri, aqui transcrita, de "Cangaceiros":

Cazuza Leutério está imaginando que há de mandar a vida inteira neste sertão. Outro dia me vieram falar de política. Foi o promotor de Alagoas de Baixo, rapaz filho dos Wanderley de Triunfo. Eu disse a ele: "--Senhor doutor, aqui quem manda é Cazuza Leutério, manda mais do que o Governo. Jatobá e Paracatu é o mesmo que fazenda dele. E está tudo acabado! Foi assim na Monarquia e assim entrou pela República. Haja rei, haja presidente, manda Cazuza e está acabado". Bem, eu quis cortar a conversa, "--Nada quero de política, senhor doutor. Fui liberal nos tempos antigos e os liberais nunca puderam aqui com o povo do pai de Cazuza Leutério. Eu sei é que, hoje era dia, de nada vale o direito do voto. Manda Cazuza Leutério nas eleições e no júri. O resto é conversa." (REGO, José Lins, 2011b, p.55)

Dessa forma, José Lins do Rego dá voz ao questionamento das instituições moldadas à forma patriarcal, questionamento esse que começou com a decadência do patriarcalismo. 
Mas também a análise do júri em José Lins do Rego deve ser vista a partir de disputas teóricas e sociológicas existentes na época sobre a relação entre o direito estatal e o direito enquanto justiça comunitária. No Brasil, ideias da escola positiva de direito penal italiana foram utilizadas por alguns juristas, a exemplo de Magarinos Torres (TORRES, Magarinos, 1934) e Roberto Lyra (SONTAG, Ricardo, 2014, 2009) para demonstrar como o júri é mais eficiente, caso sem interferência política, do que a justiça togada para realizar a justiça. Na realidade, esses autores apropriaram-se do princípio da escola positiva italiana, embora esta, paradoxalmente, fosse contra o júri (FERRI, Enrico, 1998, p.70). Segundo a escola positiva brasileira, o direito estatal só é capaz de impor as classes do crime, que, por vigerem na frieza dos planos lógicos impessoais, não são capazes de julgar os homens e os fatores concretos do crime, o que não produz justiça em relação aos costumes comunitários e individualização da pena. O júri, por ser composto de homens, que conhecem os réus e as motivações, legítimas e ilegítimas de acordo com os costumes, seria instituição mais eficiente para a satisfação da justiça. Esse pensamento teórico, acolhido pela escola positiva brasileira, mas, principalmente, acreditado como correto por muitos indivíduos daquele tempo, José Lins do Rego concede vida a ele quando trata dos temas sobre crimes passionais, por exemplo, ou sobre a vingança privada enquanto justiça no sertão, em "Pedra Bonita" e "Cangaceiros". É justo e direito, para muitas personagens, o absolvição do homicida passional ou do que fez vingança com as próprias mãos. Muitos são os discursos do tipo "está em seu direito" (Pureza) quando do cometimento dos crimes passionais. Além de o júri comportar-se pela absolvição, como no caso da personagem de Seu Samuel, da primeira parte da "Usina", que é continuação de "Moleque Ricardo". Esse é um relato histórico do direito.

Outro problema que não se soluciona fazendo história das leis refere-se ao comportamento das tropas volantes na perseguição ao cangaço e, como já dito, seu comportamento aparentemente em exceção ao direito, como quando o tenente Maurício desautoriza o Juiz de Direito na concessão de Habeas Corpus, ou nas narrativas "Pedra Bonita" e "Cangaceiro", onde se diz que as tropas vinham com poder de desautorizar qualquer pessoa, coronel ou autoridade estatal. A compreensão desse fenômeno, após dimensionado o que realmente era, precisará ingressar em aspectos teóricos sobre o Estado de Direito e comparar com a historiografia sobre regimes de exceção, a exemplo de italiana que, com Mário Sbriccoli (SBRICCOLI, Mario, 2011, p.477), desenvolveu conceitos como o de duplo nível de legalidade para a observação dos fenômenos excepcionais de repressão do banditismo italiano ou mesmo contra crimes políticos, e com Massimo Meccarelli 
(MECCARELLI, Massimo, 2011), que analisou a extraordinariedade do direito no paradoxo de sua autorregulamentação.

Dessa forma, será preciso entrar na história do pensamento jurídico-filosófico, que ultrapassa os limites de uma literatura positivista de análise das leis. Nenhum tema será tão profundo nesse âmbito do que a questão da administração da justiça no engenho e sua relação com a justiça estatal. Não se pode dizer, como faria a pura análise das leis vigentes na primeira república, que a justiça no engenho era exceção enquanto, na verdade, poderia constituir a essência do fenômeno jurídico no patriarcalismo brasileiro. O feitor que executa penas provindas da autoridade do senhor sem prévia cominação: isso não significa a princípio desvio ao direito, mas pode sim ser a própria manifestação fenomênica do mesmo enquanto na sociedade patriarcal nordestina. Em outra ponta da questão, o direito eleitoral enquanto a serviço dos senhores poderia, paradoxalmente, não implicar muitos conflitos entre a justiça no engenho e a justiça estatal, tendo em vista a íntima promiscuidade do Estado com os senhores, que formatava as leis a interesse da oligarquia dominante, assim como impedia a execução das mesmas quando lhe desagradava. Análise meramente legal dessas situações seria capaz apenas de lhes negar juridicidade. Mas não aprofundaria o exame como permite uma apreciação interpretativa.

Nesse ponto, chega-se ao limiar da análise jurídica com a análise sociológica e política do patriarcalismo. E, por isso, adentra-se no outro limite da análise factual prometida no início desta seção: a sua impossibilidade de explicar a sociedade patriarcal em suas relações socais. Como dito, José Lins do Rego herdou de Gilberto Freyre capacidade de construir nós factíveis da realidade na literatura. Não obstante, a sociologia de Freyre não se restringia a essas inferências, pelo contrário, o sociólogo pernambucano realizou uma grande interpretação do Brasil. Bernardo Ricupero demonstra a peculiaridade dos ensaios da sociologia brasileira das décadas próximas à virada do século, em que se almejavam grandes sistemas de compreensão de toda realidade (RICUPERO, Bernardo, 2011, p. 22-27). E ainda mais, além de explica, essas grandes formulações, prescreviam como deveria ser a realidade brasileira. Os ensaios possuíam cunho político prescritivo. Hoje, consolidou-se dizer de Gilberto Freyre ser o sociólogo da tradição; Sérgio Buarque de Holanda, o weberiano defensor do Estado de Direito; Caio Prado Júnior, o marxista; Oliveira Vianna e Alberto Torres, os autoritários, etc. Enfim, havia a necessidade de sistematização da realidade e a questão política dos rumos a serem seguidos.

Em se tratando de interpretações dos fatos sociais, por exemplo, Sérgio Buarque de Holanda e Gilberto Freyre divergem quanto ao aspecto da miscigenação da raça brasileira. 
Indiscutível está a promiscuidade sexual dos senhores de engenho que abusavam das mulheres escravas, sendo-lhes "dono". Não obstante, para Freyre, a miscigenação daí obtida, já que não serviu para democratizar o país em sentido econômico, serviu para democratizá-lo racialmente, com a convivência amistosa e sem preconceitos entre brancos e negros. Essa é a interpretação dada a alguns fatos, como o dos artífices ou os feitores negros sentarem-se à mesa da casa-grande, ou da amizade de brincadeiras entre os moleques e os senhorezinhos de engenho, exposta em "Menino de engenho", "Doidinho" e "Banguê". Buarque de Holanda discorda veementemente ao cunhar o estereótipo do homem cordial brasileiro, em que o relacionamento do homem branco com o negro era fenômeno de interesse, e não de real reconhecimento do negro enquanto indivíduo. Freyre foi um dos responsáveis pelo mito de que o Brasil é um país sem racismo. Concordamos com Holanda.

Em que sentido José Lins do Rego, amigo pessoal de Gilberto Freyre, irá abordar o problema da miscigenação racial e das relações raciais em sua obra? Irá se manter fiel a Freyre? Em nossa análise preliminar, aparentemente, Zé Lins caminha para a avaliação da cordialidade buarquiana. Em outra interpretação sobre a sociedade patriarcal brasileira, Buarque de Holanda retira a explicação do patriarcalismo brasileiro da estrutura autossuficiente dos engenhos. Essa independência em relação ao externo favorecia o poder do chefe local, o que criou o coronelismo, o paternalismo e o patriarcalismo típicos da sociedade brasileira, características mal avaliadas por Buarque de Holanda. Solução para o seu problema está na prescrição política. Para Holanda, o Brasil necessitava da institucionalização forte do direito estatal, garantindo as características que Weber chamou de processo de racionalização, com impessoalidade das normas a partir da burocratização e da legalidade, etc. Se José Lins critica a sociedade patriarcal em "Banguê" e no final do "Doidinho", faz o mesmo, também, com a capitalista weberiana de Sérgio Buarque em processo de formação no Brasil, como já estava evidente em o "Moleque Ricardo". O livro "Água-Mãe", ao mudar o ambiente do nordeste para o Rio de Janeiro, evidencia a todo instante o modo de os burgueses se relacionarem na busca de "relações interpessoais de prestígio e poder". Assim, nota-se crítica de José Lins a Sérgio Buarque, que considerava a "cordialidade" fenômeno devido ao patriarcalismo, que seria extinto na sociedade civil burguesa. José Lins se aproxima de análises socialistas, como a materialista marxista de seu amigo pessoal desde os tempos de Alagoas, Graciliano Ramos, em contraposição ao iluminismo burguês.

De fato, José Lins do Rego transitou entre muitas posturas políticas distintas. Sua amizade com Gilberto Freyre lhe fez ter agrados pela tradição patriarcal. Não obstante, censurada nos livros posteriores a "Menino de engenho", ou até mesmo neste, em especial 
atenção ao final do livro "Doidinho", em que Carlos de Melo, uma vez afastado do Santa Rosa para estudo, retorna e se choca com as condições dos trabalhadores. Em "Banguê", a narrativa da exploração dos trabalhadores do eito se consolida em um romance emocionante. Não obstante, o processo de urbanização marginalizante e explorador em andamento não lhe agrada, e, em "Moleque Ricardo", a "questão social" aparece. Graciliano Ramos, comunista, lê "Moleque Ricardo" na prisão, retonando em carta o seguinte comentário ao colega que lhe ajudou a sair da cadeia: "Recebi há dias $O$ Moleque Ricardo, que foi devorado em pouco tempo. (...) Vi uma nota de Carlos Lacerda, bem feita, mas uma verdadeira denúncia à polícia. Tenho a impressão de que você está aí metido em dificuldades por causa da questão social" [RAMOS, Graciliano, apud REGO, José Lins; LÊDO, Ivo (Org.), 2004, p.51] A amizade com Graciliano Ramos, que se iniciou no período em que José Lins morou em Alagoas, fez este aproximar-se de ideias comunistas e a flertar com o Partido Comunista do Brasil (PCB).

Mas de que importam as análises sistemáticas a as prescrições políticas para a análise da obra de José Lins do Rego? Não há necessidade de se falar de como a leitura política interfere na interpretação social, ainda mais quando se procuram análises sobre toda a realidade social. Interessa aqui demonstrar uma questão para a qual Antônio Cândido chama a atenção. O Brasil nos séculos de colônia e império não desenvolveu pensamento filosófico e sociológico no modelo europeu, de modo hermético e autônomo. As análises sociais e políticas tradicionalmente se realizavam dentro da literatura, a exemplo das críticas políticas de Gregório de Matos ao povo de Salvador ou dos Sermões de Padre Antônio Vieira. Machado de Assis e José de Alencar são fonte de análise para a sociedade do Rio de Janeiro do século XIX. Com o início do século XX, a publicação de "Os sertões" de Euclides da Cunha salienta essa característica, mas também engendra o seu fim. A partir de então, iniciase processo de autonomização dos campos literário e sociológico. A geração de trinta representou o ápice e o fim do ensaísmo. Textos sociológicos, como os de Freyre e de Buarque de Holanda, ainda possuem um tom lírico da narrativa, ao passo em que os textos literários se aprofundam na análise social. Nos dizeres de Antônio Cândido:

É característico dessa geração o fato de toda ela tender para o ensaio. Desde a crônica polêmica (arma tática por excelência, nas mãos de Oswald de Andrade, Mário de Andrade, Ronald de Carvalho, Sérgio Buarque de Holanda), até o longo ensaio histórico e sociológico, que incorporou o movimento ao pensamento nacional, - é grande a tendência para a análise. Todos esquadrinham, tentam sínteses, procuram explicações. Com o recuo do tempo, vemos agora que se tratava de redefinir a nossa cultura à luz de uma avaliação nova dos seus fatores. Pode-se dizer que o Modernismo veio criar condições para aproveitar e desenvolver as intuições de um Sílvio Romero, ou um Euclides da Cunha, bem como as pesquisas de um Mina Rodrigues. Sob este ponto de vista, o decênio mais importante é o seguinte, de 1930. $\mathrm{Na}$ maré montante da Revolução de Outubro, que encerra 


\begin{abstract}
fermentação antioligárquica já referida, a literatura e o pensa mento se aparelham numa grande arrancada. A prosa, liberta e amadurecida, se desenvolve no romance e no conto, que vivem uma de suas quadras mais ricas. Romance fortemente marcado de Neo-naturalismo e de inspiração popular, visando aos dramas contidos em aspectos característicos do país: decadência da aristocracia rural e formação do proletariado (José Lins do Rego); poesia e luta do trabalhador (Jorge Amado, Amando Fontes); êxodo rural, cangaço (José Américo de Almeida, Raquel de Queirós, Graciliano Ramos); vida difícil das cidades em rápida transformação (Érico Veríssimo). Nesse tipo de romance, o mais característico do período e frequentemente de tendência radical, é marcante a preponderância do problema sobre o personagem. É a sua força e a sua fraqueza. Raramente, como em um ou outro livro de José Lins do Rego (Banguê) e sobretudo Graciliano Ramos (S. Bernardo), a humanidade singular dos protagonistas domina os fatores do enredo: meio social, paisagem, problema político. Mas, ao mesmo tempo, tal limitação determina o importantíssimo caráter de movimento dessa fase do romance, que aparece como instrumento de pesquisa humana e social, no centro de um dos maiores sopros de radicalismo da nossa história (CÂNDIDO, Antônio, 2006, p.130131.)
\end{abstract}

Dessa forma, não há como aproximar-se da obra de José Lins do Rego apenas buscando nós temáticos factuais, tendo em vista a preocupação do autor em sistematizar os problemas sociais com os políticos, com os econômicos, analisar os conflitos de costumes (Água-mãe), e até mesmo inserir pouco de filosofia moral e ética nas obras ("Água-mãe", "Doidinho" e "Banguê). Por isso, se valerá também do primeiro modelo que Antônio Cândido explicou e que adentra em interpretações mais sistemáticas para explicar a realidade social narrada na obra literária. $\mathrm{O}$ aspecto biográfico servirá de norte para os pontos de partida da pesquisa, ou seja, saber as proximidades de José Lins com o comunismo, com o tradicionalismo de Freyre, com os estudos dos teóricos na faculdade de Direito do Recife. Até procurar saber quem foram os professores de José Lins do Rego na aludida faculdade será de importância.

Porém, isso não implicará reduzir a análise a algum(ns) discurso(s) vencerdor(es) sobre a realidade ou sobre algum tema jurídico. A narrativa de José Lins do Rego possui uma característica que não viabiliza vozes uníssonas. Por exemplo, em "Cangaceiros" e em "Águamãe", romances narrados em terceira pessoa, diversas personagens assumem a condução do livro, com posições divergentes, a depender do capítulo. O narrador empresta voz às personagens. Isso confere uma dimensão conflituosa que reverbera as diversas posições políticas, teórico-jurídicas, etc. da sociedade nordestina. Por isso, aquele problema de trazer as divergências filosóficas e sociológicas para a análise literária que Antônio Cândido enxergava, na verdade, para a presente pesquisa, constitui uma das maiores possibilidades de se compreender a sociedade e o direito a partir da obra de José Lins do Rego, pois explora a pluralidade. A dissonância dá voz a vários pensamentos teóricos da época. Assim, faz-se história do pensamento jurídico e político-social dentro da obra de José Lins do Rego. 


\section{CONCLUSÃO}

Pois bem, este artigo tinha como problema averiguar a possibilidade de se estudar juridicamente a obra de José Lins do Rego, escritor conhecido por buscar relatos literários que se assemelhassem à realidade do nordeste patriarcal brasileiro. O direito, entendido como um fenômeno social, precisava estar, de alguma maneira, presente na obra com verossimilhança à realidade daquela sociedade. Por isso, perguntou-se se seria e como seria possível a obra de arte aproximar-se da realidade para relatar a mesma. O teórico Antônio Cândido nos guiou na tarefa. Mas também foi feita pequena análise sobre as perspectivas do mesmo teórico, indicando predileções do mesmo frente a uma possibilidade filosófica, em detrimento a outras, e percebendo-se alternativas. Não interessava, porém, esmiuçar problemas em teoria e filosofia da obra de arte e da estética. As seis possibilidades que Antônio Cândido distinguiu para aproximar literatura da realidade social foram suficientes para o objetivo deste estudo.

Das seis possibilidades apresentadas por Antônio Cândido, intuiu-se que três poderiam ser frutíferas e, aplicando elas, se conferiu essa intuição. Em primeiro lugar, deve-se comparar a posição social do autor com a realidade social narrada. Nota-se que José Lins possui posição privilegiada, uma vez que vivenciou de perto, na qualidade de neto de senhor de engenho, aquela realidade que foi o patriarcalismo, assim como estudou direito na Faculdade do Recife. Essa é uma aproximação externa à estrutura da obra que, portanto, ajudou a confirmar intuição primeira de que é viável um estudo jurídico da obra de José Lins do Rego.

Outra aproximação que soou fértil à comparação entre a literatura de José Lins do Rego e a realidade social e jurídica foi a comparação de fatos e de situações ficcionais em homologias a fatos e a situações reais. Lembrou-se o básico sobre o regionalismo no movimento modernista, que tinha como objetivo o relato de problemas típicos daquela sociedade do nordeste da primeira república. Aprofundou-se a questão ao notar a técnica específica utilizada por Freyre, que a trouxe da sociologia americana, de buscar demarcar características específicas dos mais diversos nichos da sociedade em análise. Percebe-se, em José Lins do Rego, amigo íntimo de Freyre, esse estilo de escrita de variados nós temáticos, que vão desde a economia e a política até o folclore, a culinária e a música. A partir desses vários nós, a literatura de José Lins cria um ambiente incrível. Assim, comparar esses nós sociais e os nós jurídicos, que também foram expostos neste trabalho, com textos de época e fontes históricas torna essa forma de aproximação muito fecunda para um estudo jurídico da obra de José Lins do Rego. 
Por fim, ultima técnica elucidada por Antônio Cândido que foi percebida fecunda se refere a aproximações mais sistemáticas e teóricas sobre a realidade. Demonstrou-se que a metodologia factual de nós temáticos, exposta anteriormente, é restrita. Isso ocorre por alguns motivos. Em termos jurídicos, ela implicaria mera análise de legislações e instituições estatais. Alguns problemas presentes na obra de José Lins do Rego, como a administração da justiça dentro do engenho, o poder de política das tropas volantes com características de estado de exceção e discursos sobre o júri validando crimes passionais e vingança privada, precisam de uma análise teórica e filosófica menos factível, o que implica fazer história do pensamento jurídico, e não das leis. As fronteiras entre o pensamento propriamente jurídico e o pensamento político e sociológico se entrecruzam nesse momento, o que implica a necessidade de se analisar as perspectivas políticas existentes na época, as quais José Lins vivenciou. Outro fator que condiciona a utilização dessa forma interpretativa de aproximação entre a realidade e a literatura de José Lins é ingente devido a uma questão contingencial da literatura brasileira. Segundo Antônio Cândido, não tivemos desenvolvimento de filosofia e de sociologia nacionais durante a colônia e o império. A literatura fazia as vezes daquelas. Isso ocorre com toda a geração de 30, o ápice desse estilo, mas também o último movimento literário antes da separação dos campos. Antônio Cândido sintetiza chamando toda essa geração de tendência ao ensaísmo. Por isso, não há como fugir das perspectivas mais generalizante. Isso não significará, porém, reduzir José Lins a uma posição canônica. Pelo contrário, sua obra, por uma característica de estilo, consegue dar vozes a variadas e divergentes posições sociológicas, filosóficas, etc. ao emprestar a característica de narrador às personagens. Assim, o estilo do narrador de José Lins, presente em algumas obras, potencializa a análise interpretativa ao possibilitar identificar diversos discursos da época.

Terminada essa análise a partir das três possibilidades expostas por Cândido, conclui-se pela perfeita possibilidade de um estudo sócio-jurídico da obra de José Lins do Rego. Isso devido à sua biografia e devido aos elementos internos de sua obra, sejam factíveis ou interpretativos. Pode-se dimensionar, agora objetivos, metodologias e justificativas para a pesquisa. Como metodologia, cada tema exposto, seja de cunho sociológico, seja propriamente jurídico, deverá passar pela análise das três aproximações que se retirou de Antônio Cândido. Como objetivo geral, deverá a pesquisa retirar da obra de José Lins do Rego, com o devido auxilio metodológico, elementos sociais em sentido geral de forma a ambientar o leitor com as obras de José Lins do Rego e com a sociedade patriarcal nordestina. Como objetivo específico, se atentarás a temas jurídicos de grande complexidade presentes na obra de José Lins em homologia à realidade, a exemplo da administração da justiça no 
engenho, o poder de polícia das tropas volantes, as problemas políticos e jurídicos do júri, os direitos sociais na cidade e no engenho, e outros de menores complexidades expostos no trabalho.

Espera-se com essa pesquisa explorar a obra de José Lins do Rego em uma dimensão ainda não estudada, a jurídica. Com isso, se permitirá ao leitor leigo em direito a compreensão de alguns fenômenos atípicos para ele. Mas também permitirá ao leitor jurista uma aproximação àquela realidade nordestina que contrasta com as formas atuais do Estado, o que lhe permite até mesmo compreender melhor estas.

\section{BIBLIOGRAFIA}

ALMEIDA, José Américo. A bagaceira. 18ª ed. Rio de Janeiro: José Olympio Editora, 1980.

BROCA, Brito. Autobiografia e ficção. In: COUTINHO, Eduardo F; CASTRO, Ângela Bezarra de. José Lins do Rego. João Pessoa: Edições Funesc, 1991.

CÂNDIDO, Antônio. Literatura e sociedade. $9^{\mathrm{a}}$ ed. Rio de Janeiro: Ouro sobre luz, 2006.

CASTELLO, José Aderaldo. Origens e significado de menino de engenho. In: COUTINHO, Eduardo F; CASTRO, Ângela Bezarra de. José Lins do Rego. João Pessoa: Edições Funesc, 1991.

FERRI, Enrico. Princípios de direito criminal: o criminosos e o crime. Trad. de Paolo Capitanio. 2a ed. Campinas: Bookseller, 1998.

FREYRE, Gilberto. Casa-grande \& senzala: formação da família brasileira sob o regime da economia patriarcal. $48^{\text {a }}$ ed. São Paulo: Global, 2003.

GROSSI, Paolo. Mitologias jurídicas da modernidade. Tradução de Arno Dal Ri Júnior. Florianópolis: Fundação Boiteux, 2007.

HOLANDA, Sérgio Buarque de; ARAÚJO, Ricardo Benzaquen de (Org.); SCHWARCZ, Lilia Moritz (Org.). Raízes do Brasil. São Paulo: Companhia das Letras, 2006.

HOLlAnDA, Bernardo Borges Buarque de. ABC de José Lins do Rego. Rio de Janeiro: José Olympio Editora, 2012

TORRES, Magarinos, O Jury no Interior do Brasil: segunda conferência, na sociedade brasileira de criminologia, em 4 de fevereiro de 1933. Rio de Janeiro: Livraria Jacyntho, 1934.

MECCARELLI, Massimo. Regumes jurídicos de exceção e sistema penal: mudança de paradigma entre a idade moderna e contemporânea. In: DAL RI JÚNIOR, Arno; SONTAG, Ricardo. História do direito penal entre o medievo e modernidade. Belo Horizonte: Editora Del Rey, 2011. 
MELO FRANCO, Afonso Arinos. O espelho das águas. In: COUTINHO, Eduardo F; CASTRO, Ângela Bezarra de. José Lins do Rego. João Pessoa: Edições Funesc, 1991.

MONTENEGRO, Olívio. O novo romance de José Lins do Rego. In: COUTINHO, Eduardo F; CASTRO, Ângela Bezarra de. José Lins do Rego. João Pessoa: Edições Funesc, 1991.

PIMENTEL, Osmar. Dois meninos. In: COUTINHO, Eduardo F; CASTRO, Ângela Bezarra de. José Lins do Rego. João Pessoa: Edições Funesc, 1991.

PROENÇA CAVALCANTI, Ivan. Apresentação. In: REGO, José Lins do. Menino de Engenho. 103 ${ }^{a}$ ed. Rio de Janeiro: José Olympio Editora, $2012 b$.

RAMOS, Graciliano; LEBENSZTAYN, Ieda (org.); SALLA, Thiago Mio (Org.). Cangaços. Rio de Janeiro: Editora Record, 2014.

REGO, José Lins do. Água-mãe. 13ª ed. Rio de Janeiro: José Olympio Editora, 2012a.

Banguê. 23ª ed. Rio de Janeiro: José Olympio Editora, 2011a.

. Cangaceiros. $15^{\mathrm{a}}$ ed. Rio de Janeiro: José Olympio Editora, $2011 \mathrm{~b}$.

. Doidinho. $15^{\mathrm{a}}$ ed. Rio de Janeiro: José Olympio Editora, 1977.

. Eurídice. $10^{\mathrm{a}}$ ed. Rio de Janeiro: José Olympio Editora, 2008a.

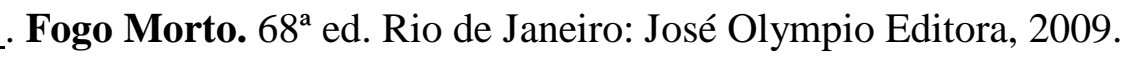

Histórias da velha Totônia. $21^{\mathrm{a}}$ ed. Rio de Janeiro: José Olympio Editora, 2010.

Menino de Engenho. 103 ${ }^{a}$ ed. Rio de Janeiro: José Olympio Editora, $2012 b$.

. Meus verdes anos. $8^{\mathrm{a}}$ ed. Rio de Janeiro: José Olympio Editora, $2008 \mathrm{~b}$.

. Moleque Ricardo. 27 ed. Rio de Janeiro: José Olympio Editora, 2008c.

. Pedra Bonita. $15^{\text {a }}$ ed. Rio de Janeiro: José Olympio Editora, 2011c.

Pureza. 12a ed. Rio de Janeiro: José Olympio Editora, 2012c.

Riacho Doce. $22^{\mathrm{a}}$ ed. Rio de Janeiro: José Olympio Editora, 2011d.

Usina. $7^{\text {a }}$ ed. Rio de Janeiro: José Olympio Editora, 1973.

REGO, José Lins; BRAGA-PINTO, César (Org.) Ligeiros traços: escritos da juventude. Rio de Janeiro: José Olympio Editora, 2007.

REGO, José Lins; CASTRO, Marcos (Org.) Flamengo é puro amor: 111 crônicas escolhidas. $3^{\text {a }}$ ed. Rio de Janeiro: José Olympio Editora, 2013. 
REGO, José Lins, LÊDO, Ivo (Org.) O cravo de Mozart é eterno. Rio de Janeiro: José Olympio Editora, 2004.

RICUPERO, Bernardo. Sete lições sobre as interpretações do Brasil. $2^{\mathrm{a}}$ ed. São Paulo: Alameda, 2011.

SBRICCOLI, Mario. Justiça Criminal. Tradução de Ricardo Sontag. Discursos Sediciosos, n. 17/18, 2011

SONTAG, Ricardo."O farol do bom senso": júri e ciência do direito penal em Roberto Lyra. Sequência (Florianópolis) [online]. 2014, n.68, pp. 213-237. ISSN 2177-7055.

Código e técnica: a reforma penal brasileira de 1940, tecnicização da legislação e

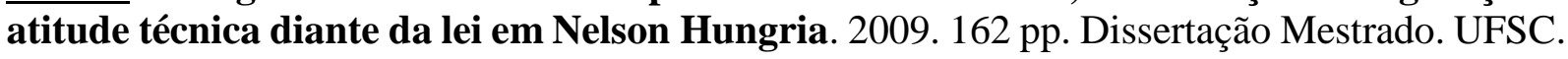
Florianópolis, 16 de novembro de 2009. 